\title{
Un análisis histórico-crítico del fenómeno de las favelas en Rio de Janeiro, Brasil
}

\section{A historical-critical analysis of the favelas phenomenon in Rio de Janeiro, Brazil}

\author{
iD Gustavo de Oliveira Figueiredo ${ }^{1}$
}

\begin{abstract}
Resumen
La ocupación del espacio urbano en Brasil es reflejo de las históricas contradicciones y luchas internas de la propia sociedad. Estudiando el fenómeno de las favelas en Río de Janeiro, se ha buscado comprender cómo se fueron constituyendo históricamente como un tema relevante para la sociedad brasileña y el modo como sus poblaciones reaccionan y luchan por mejores condiciones de vida. Se debatieron los problemas, los desafíos, las resistencias, los movimientos populares, las ideologías, la fuerza del Estado, la disputa de poder y el conflicto generado por la ocupación del suelo urbano, por la cuestión de la vivienda y los reflejos de la desigualdad y exclusión social. Se identificaron múltiples propuestas de desarrollo social y se buscó comprender cómo los distintos modelos de urbanización de la ciudad consideran la favela como causa o consecuencia de variados problemas sociales en las grandes ciudades brasileñas. Finalmente, caracterizando las fuerzas en disputa, se analizó el fenómeno en el contexto actual de cambios acelerados en que vive la ciudad por cuenta de la especulación inmobiliaria, promovida por su internacionalización.
\end{abstract}

Palabras clave: Favela; Rio de Janeiro; complexidad; desarrollo social; exclusión social

\begin{abstract}
The occupation of urban space in Brazil is a reflection of the historical contradictions and internal struggles of society itself. Studying the phenomenon of the favelas in Rio de Janeiro, we have tried to understand how they historically constituted a relevant topic for Brazilian society and how its population reacts and strives for better living conditions. Problems, challenges, resistance, popular movements, ideologies, the strength of the State, the power struggle and the conflict generated by the occupation of the urban land, the housing issue and the reflections of inequality and social exclusion were discussed. We identified multiple proposals for social development and sought to understand how the different models of urbanization in the city consider the favela as a cause or as a consequence of various social problems in large Brazilian cities. Finally, characterizing the forces in dispute, we analyze the phenomenon in the current context of rapid changes in which the city lives on account of the real estate speculation promoted by its internationalization.
\end{abstract}

Keywords: Slums; favela; Rio de Janeiro; complexity; social development; social exclusion

\author{
Tipología: Artículo de revisión \\ Recibido: $14 / 10 / 2016$ \\ Evaluado: 04/03/2017 \\ Aceptado: 07/04/2017 \\ Disponible en línea: 01/07/2017 \\ Como citar este artículo: Figueiredo, G.O. (2017). Un análisis histórico-crítico del fenómeno de las favelas en Río de Janeiro/Brasil. \\ Jangwa Pana, 16 (2), 235 - 249. DOI: http://dx.doi.org/10.21676/16574923.2131
}

1. Dr. en Psicología de la Comunicación. Coordinador del laboratorio de estudio de las ciencias. Núcleo de Tecnología Educacional para la Salud. Universidad Federal do Rio de Janeiro. Correo electrónico: gfigueiredo@gmail.com. ORCID ID: 0000-0003-2724-8826 


\section{Introducción}

$\mathrm{E}$ el estudio del fenómeno de las favelas en Rio de Janeiro, son muy comunes las investigaciones que simplifican la realidad caracterizando las favelas solamente como territorios marcados por la exclusión social y cuya infraestructura urbana es precaria; ambos aspectos determinados por el contexto de violencia. Sin embargo, de acuerdo con Figueiredo (2008), aunque estas condiciones han estado presentes en las favelas actuales, hay que tener en cuenta otras realidades silenciadas, como la lucha de la población por mejores condiciones de vida.

Este artículo se propone hacer un análisis sociológico e histórico de las favelas, discutiendo su formación como un fenómeno que es reflejo de la situación de desigualdad y exclusión social en que viven miles de personas en los países en vías de desarrollo. Tenemos el objetivo de hacer un recorrido histórico y crítico en la ciudad de Rio de Janeiro, haciendo una revisión integrativa de la literatura y teniendo como hilo conductor los conflictos sociales que conforman el fenómeno de las favelas en la ciudad.

Por un lado, es importante considerar que, oficialmente, para el IBGE (2007), "favela" es "un conjunto constituido de, por lo menos, 51 unidades habitacionales ocupando terreno o propiedad alheña, dispuesto de forma desordenada y, en su mayoría, carentes de los servicios públicos esenciales". Y, por otro lado, es necesario considerar que, en muchos casos, la complejidad de las múltiples realidades posibles cuando se habla de las favelas está, de acuerdo con Figueiredo (2012), relacionada con la etapa de desarrollo histórico en que se encuentran estos agrupamientos humanos. Para el autor:

Cuanto más tiempo existen desde su fundación, mejores serán las condiciones de vida. Las variaciones surgen aún de la capacidad de organización de cada comunidad, de la fuerza de sus asociaciones, agremiaciones e instituciones. O sea, depende de la voluntad colectiva y de la capacidad de lucha, sea para defenderse, para lograr conquistas políticas, o para mejorar las condiciones materiales de vida (Figueiredo, 2012, p. 28).

Aunque los contextos sociales, históricos y económicos sean distintos, la experiencia en Latinoamérica puede contribuir a la construcción de alternativas que ofrezcan soluciones a los problemas generados por el crecimiento urbano desordenado, evitando algunas de las consecuencias perversas que esto pueda acarrear al desarrollo humano. Las diferencias regionales son importantes para la comprensión de cada realidad y el fenómeno recibe nombres de acuerdo con los locales (favela, slums, chabolas, pueblos jóvenes o katchi obadi), sin embargo, las raíces de los procesos sociales que, en cada caso, lo configuran, tienen aspectos similares, tornándose estas poblaciones cada vez más expresivas ante las transformaciones urbanas del siglo (Ojima, 2007).

Sin embargo, si bien "la reciente substitución del término "favela" por el término "comunidad" en la política brasileña no parece haber contribuido a la comprensión de la dinámica de los procesos sociales y a la desestigmatización de los territorios (Castro, 2004, p.177), actualmente se considera que "el uso del término "favela" es un importante recurso político para que estas comunidades puedan exigir inversiones públicas y condiciones adecuadas para el desarrollo humano y para la mejora de la calidad de vida en los territorios en que viven" (Pedlowski, 2006, p.49). En este sentido, para la autora, "el referente favela estimula la lucha por los derechos, favorece la formación de nuevas asociaciones, unifica la cultura local, caracteriza la identidad propia de la gente que ahí vive y activa el desarrollo político de estas comunidades" (Pedlowski, 2006, p.52).

\section{Histórico del fenómeno favela}

El término "Favela" es definido en el diccionario principal de la lengua portuguesa como un conjunto de moradas populares desordenadamente construidas y que ofrecen a sus habitantes 
precarias condiciones de vida (Holanda, 2005). Parece ser consenso entre estudiosos del tema que el origen histórico del término proviene del primer agrupamiento de viviendas construido en un monte denominado de "morro da favela", en el centro de la ciudad de Rio de Janeiro, por los soldados que ahí se establecieron al regresar de la guerra de Canudos (Medeiros \& Chineli, 2003). Esta ocurrió entre 1896-1897 y fue un conflicto del ejército brasileño contra un movimiento popular que ocupó tierras improductivas y empezó a organizarse de forma autónoma en Bahía en el nordeste de Brasil, que sin embargo fue duramente reprimida militarmente dando como resultao la muerte de más de seis mil personas.

Sin embargo, bajo una perspectiva histórica, el proceso de ocupación de los montes de la ciudad de Rio de Janeiro (capital de Brasil de 1763 a 1960) está también asociado al proceso de esclavitud. Los esclavos que lograban huir de sus propietarios construían sus viviendas en los montes de la ciudad: áreas con vegetación densa y de difícil acceso a las fuerzas de control y represión. Con el fin de la esclavitud en Brasil, en el año de 1888, muchos esclavos, a partir de entonces, libres, junto a sus familias y a otros grupos de antiguos esclavos, se fueron a vivir a diversos montes de la ciudad (Medeiros \& Chineli, 2003).

A principios del siglo $\mathrm{XX}$, la ciudad de Rio de Janeiro ya enfrentaba graves problemas sociales, consecuencia de su crecimiento rápido y desordenado. El aumento de la población y la pobreza, agravaron la crisis de viviendas urbanas. Las viviendas y habitaciones colectivas eran una realidad creciente y las violentas epidemias de enfermedades tropicales justificaban la reputación que la ciudad adquirió como "porto sucio" (Burgos, 2007).

En las primeras décadas del siglo XX, alrededor del año 1900, el ambicioso programa de renovación urbana de la capital fue tratado como una cuestión de estrategia nacional. Sostenida por las ideas de civilización, higiene, belleza y regeneración moral, la reforma urbana de la ciudad promovió una intensa valorización del suelo urbano en el área central, lo que atingió fuertemente a la población pobre que vivía en aquella región. Miles de familias fueron trasladadas mientras las construcciones populares eran demolidas para la apertura de amplias avenidas; se construyeron muchos parques con áreas verdes y la ciudad colonial del imperio, finalmente, empezó a ser reconocida internacionalmente como "ciudad maravillosa" (Zaluar, 1996).

Sin embargo, no tan "maravillosa" para todos. $\mathrm{Ni}$ las familias desalojadas de las habitaciones populares, ni los trabajadores que emigraban a la ciudad con el objetivo de trabajar en la reforma urbanística de la capital, estaban incluidos en el plan urbanístico. Bajo estas circunstancias, el problema de las viviendas no se agravó aún más porque estas familias encontraron una solución inspirada en los soldados y en la población negra esclava que ocuparon el "morro da favela", construyendo sus viviendas en los diversos montes que hacían parte de la geografía alrededor del área central incluida en el plan de urbanización de la capital de Brasil en la época (Figueiredo, 2008).

En el contexto internacional, durante la $1^{\text {a }}$ guerra mundial (1914-1918) innúmeras familias huyen para Brasil. En aquel período, la fuerte inmigración de ciudadanos europeos contribuye en gran medida al agravamiento de los problemas sociales del país con la subida de los precios de las viviendas y el rápido aumento de mano de obra disponible que influye, a su vez, en la reducción de los sueldos. Ahora, ya eran vecinos en las favelas y se mezclaban: los soldados de Canudos, los esclavos que lograban huir, los negros libres, las familias removidas del centro en la reforma urbana, los trabajadores provenientes de todas las provincias de Brasil y los inmigrantes europeos (Figueiredo, 2012).

Cabe observar que, desde su origen histórico inicial, las favelas fueron formadas por una población excluida de la inversión pública del Gobierno que encontró soluciones propias para el problema inmediato de vivienda para sus familias. Esta relación conflictiva entre centro y periferia no fue un privilegio de Rio de Janeiro. Recordémonos 
que también en Jerusalén, Cairo, Atenas, Roma, Londres, Paris, Washington, Madrid, y muchas otras ciudades, el centro siempre fue un área privilegiada construida en base a la esclavitud, el dominioy la explotación, por los grupos que poseían el poder bélico, militar, tecnológico y/o financiero. La población que construye con el esfuerzo de su trabajo las edificaciones de las ciudades casi nunca disfruta de estas construcciones sino que terminan por construir casas en las áreas periféricas de las ciudades (Figueiredo, 2012).

La crisis económica mundial de 1929 promovió una reducción de las importaciones de productos industriales extranjeros viviendo Brasil, a partir de 1930, vive un importante periodo de industrialización y expansión de las actividades urbanas. No solo la concentración de una gran cantidad de industrias, principalmente de productos textiles y de construcción civil, sino tambiénel agravamiento de la crisis internacional del café, estimulan el éxodo rural y la inmigración hacia las ciudades. Con esto, crece el problema de la vivienda en las regiones urbanas y, en la ciudad de Rio de Janeiro, ocurre una verdadera explosión en la cantidad de favelas y en el número de su población residente.

En los años siguientes a 1940 hay una fuerte preocupación del gobierno por eliminar las favelas, por lo que se pone en marcha una política de construcción de diversos conjuntos de viviendas para trabajadores (Parques Proletarios). Además de las obras de construcción de viviendas, re realizó un programa de acciones pedagógicas con el objetivo de estimular el gusto por el trabajo y el sentimiento patriótico. Sin embargo, este proceso de educación en forma de acciones pedagógicas, asociado al trabajo realizado por la Iglesia y por el Partido Comunista Brasileño, acabó por incentivar un proceso embrionario de organización política en los habitantes de las favelas. Las reivindicaciones principales de estas primeras comisiones de habitantes eran la mejora de la infraestructura de las favelas y el no-desalojo de las familias hacia los parques proletarios. Estos fueron los primeros esfuerzos de lucha organizada por parte de la población de las favelas, dando como resultado la instalación de un sistema de abastecimiento de agua potable y electricidad (aunque bastante precario e insuficiente). Sin embargo, pese a la importante inversión en la construcción de nuevas viviendas en los parques proletarios, estas no fueron suficientes para atender la demanda creciente de la población, por lo que las favelas continuaron experimentando, a un ritmo acelerado, crecimiento poblacional y expansión territorial (Valla, 1986; Burgos, 2007; Silva, 2002).

\section{La década de 1950 y el período de la dictadura militar}

A partir de los años 1950, las favelas empiezan a aparecer de forma recurrente en los discursos oficiales como un problema fundamental de Rio de Janeiro y un locus de peligro para el orden social. Hay dos factores que resultan claves para comprender la visibilidad e importancia política que las favelas adquieren en el período: por un lado, su intenso crecimiento y, por otro, el peligro que pasan a representar frente al crecimiento de las ideas y de los grupos comunistas en el país. En 1952 fue creado el Serviço Especial de Recuperação de Favelas e Habitações Anti-Higiénicas (SERFHA) con el objetivo de intervenir en las viviendas de áreas pobres y coordinar las diversas instituciones que trabajaban con la población de las favelas. A pesar de la creación del SERFHA, se disminuye de forma considerable la inversión pública directa en la construcción de viviendas y se fortalece la propuesta de financiar y estimular que las industrias construyan edificios y vendan las viviendas a sus propios empleados (Medeiros \& Chinelli, 2003).

En el año de 1953, como resultado del esfuerzo y de la lucha de las comisiones de habitantes de las favelas, es creada, con el apoyo de la iglesia católica y del partido comunista brasileño, la Unión de los Trabajadores de las Favelas (UTF), que reunió líderes y representantes de diversas favelas. Esta surgió con el objetivo inmediato de impedir la remoción y el desalojo de las familias de la favela Morro do Borel, sirviendo de ejemplo de experiencia cooperativa entre los habitantes y 
abalanzando en los años siguientes la organización de asociaciones de vecinos en múltiples favelas do Rio de Janeiro. Con el objetivo de impedir los desalojos, la UTF organiza diversas protestas que no solo cuentan con el apoyo de los sindicatos de trabajadores, sino también con el de intelectuales y grupos progresistas. En 1957, es creada la "Coligación de los Trabajadores Favelados del Distrito Federal" (CTF-DF), un movimiento que resulta fundamental a la hora de legitimar la imagen de los habitantes de la favela como trabajadores y cambiar la imagen negativa que les asociaba a personas subversivas, peligrosas, bandidos o infractores de la ley (Valladares, 2004; Valladares, 2006).

La década de los 60 no va a ser de las mejores para la sociedad Brasileña. Inicia en 1961, con la inauguración de Brasilia como la nueva Capital Federal del país: una ciudad totalmente planificada, construida en el centro geográfico del país con el objetivo militar de servir de protección, con el objetivo estratégico de integrar mejor las 24 provincias del territorio nacional, y con el objetivo político de alejar al gobierno de las ciudades, de las manifestaciones y de la presión social. En el mismo año, atendiendo la reivindicación de la Unión de Trabajadores de las Favelas, el SERFHA propone una operación "mutirão", organizando asociaciones de vecinos en 75 favelas con el compromiso de ejecutar, en pacería con el gobierno, mejoras en los espacios de las favelas (Zaluar, 1996).

Además de eso, en los inicios de la década de los 60 es elegido como presidente de Brasil un político del partido, apoyado por las asociaciones de trabajadores con planes de ejecutar una reforma agraria, reforma de los contractos y condiciones de trabajo, y la estatización de empresas multinacionales del sector de las infraestructuras. En 1963, más de 100 líderes de las favelas se reúnen y crean la Federação das Associações de Moradores do Estado da Guanabara" (FAFEG) (Valladares, 2004; Valladares, 2006).

Realizando un análisis profundo del periodo de la dictadura militar en Brasil, Gaspari (2002) afirma que en el año de 1964 los militares brasileños, con el apoyo de empresarios, de latifundistas, de los propietarios de tierra, de la burguesía urbana y del Gobierno de Estados Unidos, en una operación militar conocida como Operación Brother Sam, realizan un golpe de Estado (Golpe Militar de 1964) tras el cual asumen el poder y el gobierno de Brasil hasta el año de 1985, alejando así lo que denominaban "peligro comunista" e impidiendo la realización de las reformas políticas de base social esperadas por los trabajadores. En 1968, el gobierno militar endurece la dictadura y publica el Quinto Ato Institucional (AI-5), cerrando el Congreso Nacional y las asambleas legislativas provinciales, suspende la Constitución e impone censura a los medios de comunicación. En el ámbito de las favelas, los conflictos se agravan: la amenaza de desalojo que siempre pesó sobre la población de las favelas, debido a los conflictos judiciales con los dueños de las propiedades privadas ocupadas, ganan graves proporciones (Gaspari, 2002).

El gobierno de la dictadura pone en ejecución una dura política de desalojo de más de 80 favelas situadas alrededor de los barrios de clase media y alta de la ciudad, con desocupación y demolición de las residencias y transferencia de las familias a conjuntos de viviendas en la periferia de la misma. La FAFEG inicia entonces una luchar que pretende tanto el retorno a la democracia, como el fin de la política de desalojo.

La resistencia de la FAFEG sufrió dura represión policial con la prisión y muerte de varios de sus líderes. A pesar de su enorme impacto social, político y humano, el programa de desalojo de las favelas no alcanzó el objetivo esperado y de 1968 a 1973 hubo un aumento de 74\% en el número de nuevas pequeñas favelas $\mathrm{y}$ un aumento de $36,5 \%$ en el número de la población de las favelas (Perlman, 1977, p. 86).

A título de ejemplo, citamos el caso de la favela "Praia do Pinto", situada en el barrio de Leblon (barrio de clase mediana-alta que tiene los valores inmobiliarios por metro cuadrado más altos de la ciudad). En 1969, después de un gran incendio sin causa determinada, cerca de 20 mil personas 
fueron desalojadas de las favelas en la periferia de la ciudad. Actualmente, aquel territorio existen diferentes conjuntos de edificaciones de lujo donde vive parte de la clase media de Rio de Janeiro (Valladares, 2004).

Ya en la década de 1970, en el ámbito social y económico, se inicia un período denominado el periodo del "segundo milagro brasileño": un periodo caracterizado por un fuerte crecimiento y desarrollo del país. El "milagro" fue financiado por préstamos internacionales que ocasionaron el crecimiento asolador de la deuda externa de Brasil. Los principales acreedores internacionales, por cierto, fueron justamente los países del bloque capitalista liderado por Estados Unidos. Y, además de esto, ocurrió, durante todo el período del "milagro brasilero" uno de los más grandes flujos migratorios de nuestra historia con el traslado de los trabajadores rurales a las ciudades (Gaspari, 2002).

Aunque una parte de esta población migratoria fue empleada por las industrias y por el comercio, otra gran parte también se quedó desempleada, agravando la situación en las favelas. Durante este período el fenómeno de las favelas se expande y se agrava en otras provincias de Brasil, con gran destaque para la provincia y ciudad de São Paulo. Por otro lado, ya a finales de la década, la política de desalojo pierde fuerza y empiezan las obras de urbanización e implantación de las infraestructuras en diversas favelas de Rio de Janeiro (Valladares, 2004).

\section{Contradicciones de la apertura democrática}

La década de los 80 `s fue un período antagónico. Si por un lado se caracterizó por una fuerte recesión (cuando el "milagro" pasa factura), por otro lado, la crisis económica debilitó el poder de la dictadura forzando el inicio de un período gradual de apertura democrática. La necesidad creciente de trabajadores en las ciudades y la presión social que representó la ocupación acelerada de las favelas hizo que la política de desalojo perdiera definitivamente fuerza en el discurso oficial. La proporción de pobres y miserables llegó a alcanzar así, en este período, el 33\% de la población total, representando en la época casi 3,2 millones de personas (Cruz-Neto, 2001).

Por otro lado, durante esta década las favelas reciben inversión pública e infraestructura en proporciones hasta entonces inéditas. El proceso de urbanización de las favelas estimula su relativa integración al espacio formal de la ciudad. Los movimientos populares hacen fuerte presión social y exigen la participación ciudadana por medio de representantes de la sociedad civil en el proceso de redemocratización del país. En 1988, entra en vigor la nueva Constitución institucionalizando el regreso de la democracia y garantizando derechos sociales exigidos por los movimientos sociales organizados que lucharon para dar fin a la dictadura.

Los años 90 significaron avances importantes para la democracia y para las luchas sociales en el país. Es en esta época que toma investidura en el cargo el primer presidente del país electo con el voto directo de la población después del fin de la dictadura. Sin embargo, en el plano político y económico, el país enfrenta problemas graves: más de 14,8 millones de familias viven en condiciones de pobreza, 45 millones de niños y adolescentes ven su desarrollo fuertemente comprometido viviendo bajo condiciones infrahumanas, de los cuales , 25 millones se encuentran en situaciones de alto riesgo social y casi 15 millones sufren de desnutrición (Cruz-Neto, 2001).

Además, la inflación llega al $1.764 \%$ por mes, exigiendo un plan de actuación de impacto: la confiscación de los depósitos bancarios por un plazo de dieciocho meses, la reducción del contingente de la administración pública, el rígido control sobre la subida de precios de los productos, la apertura del mercado brasileño a los productos internacionales por medidas de facilitación de la importación, y el inicio del Programa Nacional de Privatización de las Empresas Públicas Brasileñas en el sector de energía, telecomunicaciones, siderurgia y extracción de minerales brutos. El gobierno de Fernando Collor de Mello dura solamente dos años y, en 1992, el Congreso 
Nacional aprueba su dimisión (impeachment) por relación de sus asesores directos en amplios esquemas de corrupción (Figueiredo, 2012).

Simultáneamente, si, por un lado, se extienden las áreas de favela debido al crecimiento demográfico, al empobrecimiento de la población y ala ocupación de nuevos territorios, por otro lado, se consolida la percepción de que la favela debe ser integrada a la ciudad y se reducen los intentos de desalojo. En este sentido, según un levantamiento realizado por el Instituto Brasileiro de Estátistica (IBGE), en la década de 1990 surgieron, en la ciudad de Rio de Janeiro, más 119 favelas. Así también, en el mismo estudio, fueron identificados 513 favelas en la ciudad en el año 2000, lo que significa un crecimiento del 30,2 \% en apenas 10 años. Por su parte, en la Provincia de Rio de Janeiro (cuya capital es la ciudad con el mismo nombre) el aumento porcentual del número de favelas alcanzó el 22,7\%, dándose una ampliación de 661 a 811 favelas solamente en el período de 1991 a 2000. Por otro lado, la tasa media de desempleo entre jóvenes sube del $8 \%$ en el año de 1991 al 11,6 \% en el año de 1998 (IBGE, 2000).

Así también, en los años 90 fue establecido un nuevo modo de estratificación social que reafirmó la diferencia entre las zonas de favela y los otros barrios de la ciudad. De esta forma, las ideas opuestas de "integración" $x$ "no-integración", "ciudad" $x$ "no-ciudad", "aglomerado humano subnormal" $x$ "aglomerado humano normal", "mundo legal" $x$ "mundo ilegal", reafirmaron en el plan ideológico la demarcación y el establecimiento de fronteras sociales invisibles que en los días actuales son fuertemente reforzadas por las ideas de violencia y seguridad social (Castro, 2004).

En 1993 ocurren una serie de asesinatos en las favelas debido a que grupos de policiales deciden llevar a cabo una práctica ilegal e inmoral de exterminio de personas supuestamente involucradas en actividades ilícitas en las mismas. El evento más conocido de este caso ocurrió en la favela de Vigário Geral cuando, en una sola noche, grupos de hombres encapuchados invadieron la favela y asesinaron a 21 personas, incluyendo jóvenes, mujeres y niños (Freixo, 2012).
La opinión pública y los grupos dedicados a la defensa de los derechos humanos realizan diversas manifestaciones en la ciudad y la prensa publica una serie de reportajes denunciando la existencia de diversos grupos de exterminio vinculados a policías, empresarios y políticos actuando en las favelas de la ciudad para defender sus intereses en el comercio de drogas y de armas. Sin embargo, la violencia contra los habitantes contribuyó al fortalecimiento de las acciones de organizaciones no gubernamentales y, en una clara respuesta de la sociedad civil organizada en el mismo año, es creado en aquella favela el primer Núcleo Comunitário de Cultura del Grupo Cultural AfroReggae (GCAR) con el objetivo de ofrecer una formación cultural y artística para los jóvenes habitantes de las favelas, como alternativa al camino ofrecido por las organizaciones criminales (Cruz-Neto, 2001).

\section{Proceso de urbanización de las favelas}

En el año de 1994, el Gobierno Federal inicia un amplio proyecto nacional para urbanizar las áreas de favela en todo el territorio del país. El "Programa Habitar Brasil", se pone en funcionamiento con fondos del Banco Interamericano de Desarrollo (BID) con el objetivo de crear, ampliar o modernizar la capacidad institucional de los municipios para actuar en la mejora de las condiciones de vivienda de las familias pobres. Esto se logró mediante la implantación coordinada de proyectos integrados de urbanización de ocupaciones irregulares que buscaban la regularización de propiedades, la implementación de infraestructura urbana y la recuperación ambiental de las zonas de favela, logrando la movilización y participación de los habitantes en la concepción, coordinación e implementación de los proyectos (Brasil, 2008).

En el mismo año, se inician también las actividades del Programa Favela-Barrio; sin embargo, como herramienta para la urbanización e integración social, este programa no resulta exitoso en su objetivo de recuperar y evitar la degradación de la periferia urbana. De acuerdo con Silva-Junior (2006): 
El cambio esencial que se establece en la década de los noventa, en las intervenciones de la Alcaldía de Rio de Janeiro, fue contraponerse a la idea de subsanar únicamente el déficit habitacional existente, sustituyéndola por la noción de superación del déficit urbano a través de la "producción de la ciudad". Es decir, sustituir la acción aislada de construir casas, por la organización de una estructura urbana, donde los estratos de población excluidos de los servicios públicos se integren a la dinámica funcional y vital de la ciudad formal". (p. 228)

En total, con este programa se verían beneficiadas, con obras de infraestructura y urbanización, 168 favelas en la ciudad de Rio de Janeiro. Sin embargo, muchos autores critican el Programa Favela-barrio denunciando que si bien este debía concluirse en marzo de 2004, las obras no fueron realizadas en su totalidad (Figueiredo \& Wimmer, 2006; SilvaJunior, 2006; World Bank, 2004). Los estudios indican que la prioridad de inversión pública del ayuntamiento, durante el gobierno del alcalde César Maia, se concentró en el desarrollo de obras para la realización de los juegos Panamericanos en Río de Janeiro en el año de 2007, estando marcado por la corrupción activa (Silva-Junior, 2006). De acuerdo con el Banco Mundial(World Bank, 2004), este plan proporcionaría la tanto la reedición del programa Favela Barrio, como la ampliación de las comunidades beneficiadas por el programa; sin embargo, debido a que se presentadon un sinnúmero de problemas en la prestación de cuentas por parte del gobierno municipal, el banco mundial limitó los préstamos para la segunda etapa del programa. Aún de forma más radical, Leite \& Silva (2004) critican el programa y afirman que el Favela Barrio no garantizó, y ni siquiera propició, un mejor acceso de los habitantes a los derechos de ciudadanía.

Los movimientos sociales populares sufrieron cambios importantes durante este período. No solo surgen nuevos movimientos contra la violencia, la corrupción, el corporativismo y la impunidad, sino que, además, el Movimiento de los Trabajadores Rurales Sin Tierra (MST) pasa a ser el más grande movimiento popular en el país que repercute incluso en los grandes centros urbanos, donde estimula el surgimiento del Movimiento de los Sin Techo (también con la sigla MST). Las diferencias sociales y la estigmatización de la pobreza profundizan las percepciones negativas de las favelas y de los pobres, lo que es, de acuerdo aún con las mismas autoras, una reedición contemporánea del "mito de las clases peligrosas" donde la población de las favelas, y principalmente los jóvenes que viven en ellas, pasan a ser considerados como criminales en potencia (Medeiros \& Chinelli, 2003).

Por otro lado, la década de los 90 trae una gradual desmovilización política para las favelas. Aunque las asociaciones de vecinos existieran en casi todas las favelas, las actividades sociales fueron burocratizadas, mientras que las asociaciones populares estuvieron de tal forma controladas por el poder público que pasaron simplemente a gestionar algunos servicios urbanos en su territorio y a ser ignoradas por gran parte de la población local (Fausto-Neto, 1995). Otra dimensión que contribuyó a la debilitación del poder de movilización y a la lucha por parte de las asociaciones de vecinos, fue su creciente relación con organizaciones criminales que, en muchas favelas, presentaron candidatos propios. La dominación, mediante el miedo, promovió la corrupción de las organizaciones populares en las favelas y generó la persecución y muerte de líderes que intentaron denunciar la toma del poder por parte de las organizaciones criminales (Zaluar, 1996).

Por lo tanto, esta década puede también ser considerada como el período en el que las facciones criminales responsables por el comercio de drogas y de armas expandieron sus actividades en las favelas. Con esto, se puede verificar también en el período el aumento creciente de la violencia y de la participación de los jóvenes como empleados de dichas organizaciones criminales. La violencia, el miedo, el dominio de los criminales y la histórica incapacidad del Estado para solucionar los problemas de vida de la población de las favelas son factores que agravan los conflictos y empeoran considerablemente la calidad de vida de sus habitantes (Cruz-Neto, 2001). 
El crecimiento del número de Organizaciones No Gubernamentales (ONG), asociaciones y otras instituciones con actividades de intervención social en las favelas, tiene dos vertientes a considerar: por un lado, el gobierno financió acciones y estableció pacerías con la sociedad civil con el objetivo de reducir los gastos en el sector público y transferir la responsabilidad de la gestión e implementación de acciones sociales para la sociedad civil. Por otro lado, la sociedad civil se organizó y empiezó a proponer acciones en las favelas con el objetivo de reducir los conflictos sociales y el riesgo creciente que representaba la violencia para la sociedad (Zaluar, 1996).

En 1998, un grupo de jóvenes provenientes de las favelas de Rio de Janeiro, que estimulados por las intervenciones sociales promovidas por el movimiento Hip Hop, se organiza para fundar la "Central Única das Favelas" (CUFA), una Institución que tiene como principal objetivo crear espacios en la ciudad para la expresión de los movimientos populares provenientes de las favelas. La creación de la entidad representa una iniciativa de organización que proviene dela propia población joven de la favela y que es, por tanto, independiente de las asociaciones de vecinos y que cuenta con las herramientas apropiadas de la organización institucional de la sociedad civil. Actualmente, la CUFA tiene representantes en diversas provincias de Brasil y agrupa innumerables instituciones sociales que actúan en las favelas del país(Medeiros \& Chinelli, 2003).

\section{Las favelas en la actualidad}

Con el intento de frenar la escalada de la violencia y de la violación de los derechos humanos en el país, el gobierno brasileño, presionado por la sociedad civil y por los organismos internacionales, realiza en marzo de 2000 la Conferencia Nacional de Derechos Humanos, que significó un importante avance al adoptar una posición positiva, discursiva e institucional, que permitió la composición de una amplia red de fiscalización de los derechos humanos. Sin embargo, en el período del gobierno de Fernando Henrique Cardoso, el Estado brasileño fue identificado como el más grande agente violador de los Derechos Humanos en el país por las más relevantes Organizaciones No Gubernamentales Internacionales de Derechos Humanos en el Mundo (Ballestrin, 2007).

En el 2001, el "Instituto de Estudios Trabajo e Sociedad" (IETS), una Institución privada sin fines lucrativos de la sociedad civil, desarrolla un programa denominado "Observatorio de Favelas do Río de Janeiro" que a partir del 2003 amplía sus acciones y se constituye en una Organización No Gubernamental integrada por investigadores y estudiantes vinculados a diferentes instituciones académicas y organizaciones comunitarias. Sus principales coordinadores son habitantes o exhabitantes de favelas de Rio de Janeiro que concluyeron la universidad y preservaron sus vínculos e identidades con el territorio de origen. La Institución actúa desde entonces como una red de formación de líderes y presta asesoría a acciones innovadoras en las favelas de Río de Janeiro (Figueiredo, 2012).

El 2003, por su parte, es el año en el que inicia el primer gobierno del presidente Luís Ignacio Lula da Silva, perteneciente al Partido de los Trabajadores (PT). El gobierno de Lula se caracteriza por los buenos resultados económicos, entre los que se encuentran la baja inflación y la alta tasa de crecimiento del Producto Interno Bruto (PIB). Así también, se da un gran avance en la reducción de las desigualdades, con perceptible mejora social: reducción del desempleo, reducción de la tasa de pobreza, transferencia directa de renta para familias en situación de extrema pobreza, fuerte ampliación de los niveles de escolarización y reducción del analfabetismo. Por esto, se trata de un gobierno que fue aún muy importante para la elevación de la autoestima de los brasileños (Figueiredo, 2012).

En el mismo año, se publica uno de los primeros libros de literatura no científica que desvela las conexiones entre grupos de empresarios, jueces, políticos y otras personalidades de la vida pública de Rio de Janeiro, relacionados con el tráfico de 
drogas en la favela. El periodista torna público el modus operandi de las corporaciones criminales y mafias que controlan el tráfico de drogas y otras actividades ilícitas a partir del estudio del caso de una de las más importantes favelas de la ciudad, el Morro Dona Marta (Barcelos, 2003).

En los últimos años, tanto por el crecimiento acelerado de las favelas, como por la violencia generada por la acción del tráfico de drogas, por la pobreza y por la exclusión social, la prensa, el cine y diversas organizaciones de la sociedad civil han retomado el debate de los problemas que afectan la vida de la gente que vive en las favelas y la sensación de inseguridad que respecto a ellas sienten las clases medias y altas. Si bien la sociedad es consciente de que es necesario intervenir, muchas veces las opiniones son contradictorias en la forma como se debe hacer esta intervención (Barcelos, 2003).

Aquella tensión revela la crisis. Por un lado, hay quienes dicen, en una actitud claramente prejuiciosa y racista, que es necesario que la policía y el ejército ocupen las favelas y exterminen a toda la gente que se relaciona con el crimen organizado; actitud que, por supuesto, desconsidera que la dirección del crimen organizado no vive ahí. Y, por otro lado, están los que dicen que es necesaria una mayor inversión por parte del gobierno para garantizarle a esta población unas mínimas condiciones de vida. Así lo es para Soares, Bill \& Athayde (2005), quienes publican el libro "Cabeça de Porco", en el que se revelan detalles impresionantes acerca de la realidad de niños y jóvenes que viven en las favelas y trabajan para las mafias. Este, surge de una larga investigación sociológica realizada en diversas provincias de Brasil, y presenta por medio de entrevistas, relatos, datos estadísticos y otras fuentes de información el drama humano y las dimensiones de la exclusión y de la violencia en que viven estos jóvenes, lanzando un panorama realista acerca de la violencia en Brasil y del modo como esta afecta la vida de los jóvenes pobres (Soares, et al., 2005).

El 19 de marzo del 2006 se transmite en cadena nacional por la televisión abierta el documental
"Falcão: Meninos do Tráfico", producido por la Central Única de Favelas (CUFA). Este reportaje aborda la dura realidad en medio de la que viven niños y adolescentes que trabajan para las mafias y corporaciones criminales que controlan el tráfico de drogas y otras actividades ilícitas en Brasil, y revela de forma impactante imágenes reales y entrevistas con los jóvenes sin cortes o ediciones. Los directores del documental hicieron un seguimiento longitudinal de la vida de 17 jóvenes en el periodo 1998-2006. De estos jóvenes, 16 fueron asesinados y solamente uno sobrevivió. En las entrevistas, los adolescentes no solo hablan de sus historias de vida, de la relación con la familia, del trabajo en el tráfico de drogas, sino que también enseñan sus armas de fuego, explican cómo manipulan la droga, cómo la venden, hablan del sueldo que reciben por su trabajo, reclaman oportunidades distintas y critican la escasez de políticas para jóvenes. El documental choca con la opinión pública y con la sociedad brasileña, causando indignación y provocando diferentes revueltas contra la situación, dada la crudeza y verdad conque enseñaba la dura realidad de los jóvenes (Figueiredo, 2012).

Así, a través del documental la sociedad mira a los ojos de los jóvenes a quienes niega oportunidades $\mathrm{y}$ de quienes tiene miedo. Al traer al público sus discursos, la prensa abre espacio al debate y provoca la opinión pública. El documental es exhibido íntegramente $\mathrm{y}$, a la semana siguiente, se repite de manera parcial. Mientras expertos debaten en la televisión la situación, las causas y los efectos, el gobierno se ve obligado a pronunciarse y a explicar sus políticas públicas. El tema de la seguridad entra en pauta y se establece como tema importante para la sociedad, para el gobierno y para las favelas. Así, surgen nuevas denuncias, las asociaciones de la sociedad civil reclaman más acción, y el tema gana fuerte relevancia nacional (Figueiredo, 2012).

A finales del 2007, como parte de su política de desarrollo para el país, el gobierno de Lula lanza el PAC (Programa de Aceleración del Crecimiento) que se constituye en un plan de inversión pública en áreas prioritarias para el desarrollo del país. 
En el plan están previstas obras de infraestructura energética, de transportes, de producción agrícola y también de recuperación urbana de áreas de favela. Como resultado de esta política de inversión, fueron beneficiadas con obras de urbanización y de instituciones para el desarrollo social algunas de las más grandes favelas da ciudad de Río de Janeiro (Nepomuceno, 2008).

En abril del 2008 se estrena en el Festival de Cinema de Rio de Janeiro la película "Tropa de Elite", que aborda la temática de la violencia desde la perspectiva de la policía. El documental describe las acciones de un grupo policial oficial especializado en el combate del tráfico de drogas (Batallón de Operaciones Policiales Especiales - BOPE) y revela la forma violenta como son llevadas a cabo las operaciones policiales en las favelas. Además de eso, denuncia el abuso de poder de los policiales, la violencia generada por esos órganos de represión del estado brasileño, y la legitimidad que poseen frente a las clases media y alta de la sociedad brasileña. La película presenta fuertes escenas de tortura, estupro, agresión y otras formas de violencia practicadas por la policía en las favelas de Brasil. Sorprendentemente, la sociedad se fragmenta en cuanto a la crítica sobre estas formas de violencia y crecen las manifestaciones públicas de apoyo al ejercicio del poder de forma violenta por la policía en detrimento a todo el discurso a favor de los derechos humanos. Sin embargo, un representante de los deputados estaduales afirma públicamente que en algunas favelas de Río de Janeiro el crimen organizado está controlado por la propia policía que, además del comercio de drogas, controla la seguridad, la distribución del gas de cocina y el transporte en el interior de las favelas (Freixo, 2012). Esta Denuncia se hace pública con la secuencia de la película Tropa de Elite 2: agora o inimigo é outro, cuando se revelan los bastidores sucios de la política de seguridad pública del Gobierno de Rio de Janeiro (Figueiredo, 2012).

Innumerables entidades, $\mathrm{ONG}^{\prime} \mathrm{s}$, asociaciones profesionales e instituciones académicas de enseñanza e investigación alertan sobre el hecho de que la sociedad no puede despreciar la historia de formación de las favelas ni tampoco aceptar la violencia institucional oficial como forma de combatir los problemas generados por la exclusión social, la mala distribución de la riqueza y la grave crisis generada por el crecimiento acelerado de la influencia y el poder de las mafias y corporaciones criminales. Aunque se dieron esfuerzos por hacer más crítico el debate y ponerlo en el contexto de la compleja problemática social que se presentaba en las favelas, la prensa divulgaba tanto la forma en que el público aplaudía la acción violenta de los policiales en la pantalla, como las cartas de lectores que se manifestaban a favor de las acciones de represión llevadas a cabo por la fuerza policial (Figueiredo, 2016).

Aún en los inicios del 2008, el terror es importado directamente desde las pantallas. La policía y el ejército brasileño hacen una mega operación militar en la que las fuerzas de represión del Estado ocupan las favelas. Como resultado de la operación, identificada como el primer estadio del Plan de recuperación de las favelas, las organizaciones de defensa de los derechos humanos denuncian el terror vivido por la población a causa de la brutalidad de la misma que, solamente en una de las favelas, culminó con la muerte de más de 50 personas, instalando entre los habitantes la sensación de inseguridad (Castro, 2004).

Como afirma Figueiredo (2016), el impacto de las acciones militares en la opinión pública, la polémica encendida por las innumerables denuncias de violación de los derechos humanos y las revueltas populares de la gente de las favelas con manifestaciones, son acciones reivindicativas concertadas de las asociaciones de vecinos. La presión realizada por la prensa nacional e internacional, hace que el presidente Luis Ignacio Lula da Silva vaya personalmente a algunas de las más pobladas favelas de Rio de Janeiro para calmar a la población e inaugurar las obras del Programa de Aceleración del Crecimiento (PAC), que aporta importantes inversiones en algunas favelas de las grandes ciudades. Como es publicado por el periódico El País en España (Nepomuceno, 2008): "el proyecto beneficiará las comunidades con la apertura de calles, la ampliación y mejora de la red 
de desagüe, servicios de limpieza urbana, puestos de salud, guardería infantil y complejos deportivos".

El periódico afirma también que la favela da Rocinha, donde viven alrededor de 130 mil personas, recibirá inversiones de aproximadamente 75 millones de euros; la favela de Manguinhos, donde viven 45 mil personas, contará con unos 110 millones de euros, y el conjunto de favelas denominado Complexo do Alemão, con 100 mil personas, recibirá una inversión de 220 millones de euros. La inversión total en las favelas de Rio de Janeiro y São Paulo significa la mayor dotación jamás destinada a obras estructurales en favelas en el país (Nepomuceno, 2008). Por otro lado, como afirma Figueiredo (2012):

Esta generación de jóvenes que vive en las favelas de Rio es más educada que nunca, tienen acceso - aunque de forma escasa - a la cultura, a los medios de comunicación, a la informática, y son fruto del trabajo casi invisible de innumerables individuos, grupos, colectivos, asociaciones, organizaciones, fundaciones y empresas que vienen desarrollando en las últimas décadas un importante trabajo de concienciación política, de desarrollo de capacidades humanas, de formación, de organización. La población de las favelas sabe que sus condiciones de vida y que sus posibilidades y oportunidades de futuro son muy diferentes de la gente de la clase media $\mathrm{y}$ alta con quien conviven diariamente en el ir y venir de la ciudad. Muchos se rebelan, muchos son agresivos, muchos optan por caminos arriesgados, y muchos se esfuerzan por cambiar esta realidad. (p.52)

Muy bien definió la favela el grupo cultural Afro Reggae, como ya decimos, una de las asociaciones más activas en Río de Janeiro: "las favelas son heridas abiertas en la ciudad". Por todo esto, necesitan de cuidados, de atención y de intervención social. Sin embargo, "A favela, se 'inventa' ao longo de uma história secular que, do mito de origem e passando pelo discurso científico, leva, contra toda expectativa, a uma consagração cultural e midiática" (Valladares, 2004, p. 34).

\section{Las fuerzas en disputa}

En el año 2010, se inicia en Rio de Janeiro una nueva política de control policial de las favelas. Con el nombre de Unidad de Policía Pacificadora, conocida en Brasil bajo la sigla UPP, el gobierno vuelve a intervenir en el territorio de las favelas con una fuerte política de represión policial contra las mafias del tráfico de drogas. Se inicia así un plan de intervención militar basado en el discurso del desarrollo, sin embargo, fracasó al no aportar cambios significativos en el contexto de exclusión social y por no recuperar en definitivo el territorio tomado por las mafias.

Con la perspectiva de recibir el mundial de fútbol en el año 2014, y los juegos olímpicos en el año 2016, se inicia en Rio de Janeiro una fuerte política de represión en las favelas y un maquillaje de la zona central y sur de la ciudad para recibir a las personas que vendrán de diferentes partes del mundo. Por un lado, el incremento del turismo y de las inversiones en infraestructura representa importantes avances para la ciudad. Sin embargo, por otro lado, esta preparación para la inserción definitiva de la ciudad de Rio de Janeiro en el panorama turístico internacional crea un fuerte factor de tensión social, dado que genera aún más contradicciones y disparidades entre las clases sociales y amplía la angustia de aquellos que no están inseridos en este proyecto político de desarrollo (Figueiredo, 2012).

El conflicto se agrava y aumenta la tensión generada por la forma de concebir el espacio físico-social de las favelas como una realidad dividida y en confrontación constate entre el bien y el mal. En este sentido, Turcheti (2010) se refiere a las políticas públicas que aplican medidas desafortunadas para corregir las consecuencias negativas asociadas a la marginalidad y pretenden, a su vez, descubrir los aspectos más positivos del "ser" de las favelas como, por ejemplo, la cultura carioca. Ante esta percepción dual y contradictoria, surge la propuesta de romper 
con la estigmatización de las favelas e iniciar la construcción de un nuevo discurso, más allá de la dualidad, asentado en la premisa de que la favela es una parte de la ciudad que debe ser reconocida y tratada como tal para que las políticas y las intervenciones trabajen desde la inclusión.

Actualmente, en el año 2012, la política local en Rio de Janeiro sigue tratando a la población de las favelas de forma discriminatoria e irresponsable. Programas de Seguridad Publica como las Unidades de Policía Pacificadora (UPP) son implementados solamente en su vertiente represiva, con muy pocas acciones sociales efectivas $u$ obras de infraestructura urbana. Excepto por las inversiones directas del gobierno federal en las favelas más pobladas $\mathrm{y}$, por lo tanto, más conflictivas, no existe un plan de inversión municipal o estadual para la recuperación de las áreas de favela: no hay obras de construcción de nuevas escuelas, no hay inversión real en la red de salud pública, no hay obras para la construcción de espacios para el ocio y el desarrollo cultural y no hay una política para la formación profesional de los jóvenes. Y sí hay, en cambio, un intento de remoción de las favelas ubicadas en zonas cercanas a los lugares donde se llevan a cabo obras de infraestructura para los juegos olímpicos (Figueiredo, 2012).

En el panorama político actual, esta grave situación se repitió con la movida que se hizo en la ciudad para el campeonato mundial de fútbol en el 2014 y la higienización social hecha para la realización de las olimpíadas en el 2016. Asociado al crecimiento económico, a la disminución de la pobreza, al superávit de la balanza comercial, a los indicadores económicos positivos y a la mejora de los indicadores de educación, salud y reducción de la desigualdad, habrá que actuar junto a la población que vive en las favelas ofreciendo oportunidades y políticas concretas para que también puedan desarrollarse. La violencia policial no disminuye $\mathrm{y}$, frecuentemente, la prensa denuncia el agravamiento de los conflictos sociales. Así, por ejemplo, en septiembre del 2011 fueron divulgadas fotografías de las fuerzas policiales abordando niños, poniéndolos contra la pared, revisándoles los bolsillos y las carpetas de la escuela como si fueran adultos o jóvenes infractores. Por otro lado, las frecuentes denuncias de corrupción por parte de los políticos y de la policía generan protestas anti-corrupción en las calles. Es frecuente la demisión y el cambio del comando policial en las favelas 'pacificadas' (Figueiredo, 2008, 2012, 2016).

Brasil aún presenta graves contradicciones sociales incompatibles con el status de desarrollo humano que se desea. Es posible verificar que la exclusiónsocial es una potente arma que utilizada por los ricos para hacer prevalecer su poder, siendo indiferentes ante las terribles consecuencias que esta genera, dado que priva el derecho a la calidad de vida. Asociado al crecimiento económico, a la disminución de la pobreza, al superávit de la balanza comercial, a los indicadores económicos positivos y a la mejora de los indicadores de educación, salud y reducción de la desigualdad, Brasil habrá que actuar junto a la población que vive en las favelas ofreciendo oportunidades y políticas concretas para que también puedan desarrollarse. Sin embargo, la situación aún es crítica y exige atención (Preteceille \& Valladares, 2000). Durante los últimos meses, como nos señala Figueiredo (2016):

La prensa sigue divulgando los conflictos en las favelas. Cada día son asesinados más jóvenes, cada semana mueren decenas de inocentes, cada mes la gente de la favela sufre con invasiones de grupos rivales y con la violenta intervención policial. El problema gana cada día dimensiones de mayor impacto en la opinión pública y verdaderamente se constituye como el principal problema a ser afrontado por la sociedad brasileña en rumbo a su desarrollo. (p. 2.448)

Se trata, para el autor, de un problema relacionado con la desigualdad y con la exclusión social que, verdaderamente, se constituye como uno de los más desafiadores problemas a ser trabajado por la sociedad brasileña. En este sentido, es posible observar que, con las multitudinarias manifestaciones en las calles, ocurridas en el 2013, la población percibió que las contradicciones del 
país y su historia de corrupción política no podían seguir ocurriendo impunemente. Sin embargo, las fuerzas de derecha, reaccionarias, temerosas de las crecientes protestas y los avances sociales logrados por los gobiernos progresistas del partido de los trabajadores, organizaron un nuevo golpe de Estado en Brasil, ocurrido en el año 2016. El impedimento político de la presidenta Dilma Roussef, sin que hubiera cometido crimen alguno, provocó la interrupción de la democracia. El gobierno ilegítimo que asumió la presidencia de Brasil con el golpe de Estado amplió los recortes de derechos sociales, aceleró las reformas neoliberales y avanza rápidamente en el sentido de ampliar la desigualdad social cargando a los trabajadores y ejecutando políticas económicas que perpetúan los privilegios de los ricos.

Con todo esto, la crisis económica lleva el país al borde de un colapso social. ¿Qué pasará con las favelas en las próximas décadas? No sabemos. Todavía hay muchas posibilidades de futuro, que será el resultado de todas las fuerzas sociales que hoy actúan en pos del cambio de esta realidad. En Brasil, durante el transcurso del 2017, han vuelto a ocurrir grandes protestas populares por todas las capitales. La población sigue luchando contra las reformas neoliberales y los recortes de derechos sociales. Los escándalos de corrupción se transforman casi en una telenovela, explotada al máximo por la prensa hegemónica. Hay enfrentamientos violentos de la población contra las reformas laborales y contra la previdencia social que en nombre del llamado "ajuste fiscal" acaba por recortar derechos y aumentar la desigualdad social. Cuanto más se amplía la desigualdad y la exclusión social en Brasil, más crítica se hace la vida en las favelas, ampliándose los conflictos urbanos y llegando al nivel de poner en riesgo los contratos sociales y la paz en el país.

\section{Agradecimientos}

Gracias a la Agéncia Española de Cooperación Internacional y Desarrollo del Ministério de Asuntos Exteriores de España por la beca de investigación en la Universitat Autónoma de Barcelona.

\section{Referencias bibliográficas}

Ballestrin, L. (2007). Direitos Humanos, Estado e Sociedade Civil nos Governos de Fernando Henrique Cardoso (1994-2002). Minas Gerais: FCP/UFMG.

Barcelos, C. (2003). Abusado: O Dono do Morro Dona Marta. Rio de Janeiro: Record.

Brasil. (2008). Programa Habitar Brasil. Convênio de Cooperação Banco Interamericano de Desenvolvimento e Casa Civil da Presidencia da República do Brasil. Brasília: BID-Brasil.

Burgos, M. (2007). Escola, favela e cidade no Rio de Janeiro. Fórum de Debate: Innovaciones Locales ante Inseguridades Globales - los casos de Brasil y España. Barcelona: CIDOB.

Castro, J.P. (2004). Da favela à comunidade: Formas de classificação e identificação. Revista Anthropológicas, 15(2), 171-98.

Cruz-Neto, O., Moreira, M. \& Sucena., L. (2001). Nem Soldados, Nem Inocentes: Juventude e tráfico de drogas no Rio de Janeiro. Rio de Janeiro: Editora Fiocruz.

Fausto-Neto, A. (1995). Violência e Dominação: as favelas voltam à cena. Revista Sociedade e Estado, 10(2), 417-438.

Figueiredo, G.O. (2008). Desarrollo Humano en Contextos de Exclusión Social y Violencia: Los Jóvenes en Favelas de Río de Janeiro, Brasil. (Tesis de maestría). Facultad de Psicología-Universidad Autónoma de Barcelona, Barcelona, España.

Figueiredo, G.O. (2012). Promoción del Desarrollo Humano con Jovenes en Favelas de Rio de Janeiro/ Brasil: Vulnerabilidad, Resiliencia e Intervención Social. (Tesis doctoral). Universidad Autónoma de Barcelona, Barcelona, España. Recuperado de https://www.educacion.gob.es/teseo/imprimirFichaConsulta.do?idFicha=319329\#

Figueiredo, G.O. (2016). Los jóvenes en favelas de Rio de Janeiro, Brasil: de la vulnerabilidad social a las oportunidades para el desarrollo humano. Ciência \& Saúde Coletiva, 21(8), 2437-2450. Doi: https:// dx.doi.org/10.1590/1413-81232015218.01622015 
Figueiredo, G.O. \& Wimmer GF. (2006). Ação Coletiva para a Qualidade de Vida. Ciência \& Saúde Coletiva, 11(1), 145-154. Recuperado de http:// www.scielo.br/pdf/csc/v11n1/29458.pdf

Freixo, M. (2012). Prisões, crime organizado e exército de esfarrapados. Rio de Janeiro: Ong Justiça Global. Recuperado de: https://www2. mp.pa.gov.br/sistemas/gcsubsites/upload/60/ Pris $\%$ C3\%83\%C2\%B5es, \%20crime $\% 20$ organizado $\% 20 \mathrm{e} \% 20 \mathrm{ex} \% \mathrm{C} 3 \% 83 \% \mathrm{C} 2 \%$ A 9 rcito $\% 20 \mathrm{de} \% 20$ esfarrapados.pdf

Gaspari, E. (2002). A Ditadura escancarada. São Paulo: Cia. da Letras.

Holanda, A.B. (2005). Dicionário Brasileiro da Lingua Portuguesa. Rio de Janeiro: Ediouro.

Instituto Brasileiro de Geografia e Estatistica (IBGE). (2000). Censo Populacional Brasileiro no ano 2000. Rio de Janeiro: IBGE.

Instituto Brasileiro de Geografia e Estatística (IBGE). (2007). Indicadores Sociais Mínimos: Pesquisa Nacional por Amostra de Domicílios no ano de 2006. [CD-ROM]. Rio de Janeiro: Instituto Brasileiro de Geografia e Estatística.

Leite, M. \& Silva, A. A. (2004). Democracia vista de baixo: favelas e democracia, temas e problemas da ação coletiva nas favelas cariocas. Rio de Janeiro: IFICS-UFRJ.

Medeiros, B. \& Chinelli, F. (2003). Favela e redes solidárias: formas contemporâneas de mobilização e organização popular no Rio de Janeiro. Urbanización latinoamericana a finales del siglo $X X$, presentado en la conferencia final del proyecto, Montevideo, Uruguay.

Nepomuceno, E. (2008). Lula se propone rehabilitar las favelas y acabar con la violencia. El País. Recuperado de http://internacional.elpais.com/internacional/2008/03/08/ actualidad/1204930801_850215.html

Ojima, R. (2007). As Cidades Invisíveis: a favela como desafio para urbanização mundial. Revista Brasileira Estudos de População, 24(2), 345-347.
Pedlowski, A. (2006). Desenvolvimento Sustentável: Estado, Ambiente e Movimento Sociais. Projeto de Pesquisa CAPES. Rio de Janeiro: Universidade Estadual do Norte Fluminense.

Perlman, J. (1977). O Mito da Marginalidade: Favelas e política no Rio de Janeiro. Rio de Janeiro: Paz e Terra.

Preteceille, E. \& Valladares, L. (2000). A desigualdade entre os pobres: favela, favelas. En: R. Henriques. (Org), Desigualdade e pobreza no Brasil (pp. 45985). Rio de Janeiro: Ipea.

Silva-Junior, L. (2006). O Programa Favela-Bairro e as Políticas Habitacionais do Banco Interamericano de Desenvolvimento. Rio de Janeiro: Universidade Federal do Rio de Janeiro.

Silva, L.M. (2002). A Continuidade do "Problema Favela". En: L. Oliveira. (Org), Cidade: história e desafios (pp. 220-37). Rio de Janeiro: FGV.

Soares, L., Bill M. \& Athayde, C. (2005). Cabeça de Porco. Rio de Janeiro: Objetiva.

Turcheti, N. M. (2010). Public policy for the favelas in Rio de Janeiro: the problem (in) framing. (Tesis) The Netherlands: Graduate School of Developmentet Studies, The Netherlands Recuperado en https://thesis.eur.nl/pub/8698/_RP_Nicole_Melo.pdf.

Valla, V. (1986). Educação e Favela: políticas para as favelas do Rio de Janeiro entre 1940-1985. Petrópolis: Vozes.

Valladares, L. (2004). O Rio de Janeiro na virada do século: mercado de trabalho, violência e formas de mobilização e ação coletivas. Rio de Janeiro: IUPERJ.

Valladares, L. (2006). La favela d'un siècle à l'autre: Mythe d'origine, discours scientifiques et représentations virtuelles. Paris: Éditions de la Maison des sciences de l'homme.

World Bank. (2004). Case study summary: Brazil/ Favela-Bairro/ Scaled-up Urban Development, Shanghai Poverty Conference. Washington: World Bank.

Zaluar, A. (1996). Medo e Política: A crise nas associações de moradores. Lei e Ordem, 47(15), 25-27. 